\title{
A Catenary Analysis of the Maxillary Dental Arch During Human Embryogenesis '
}

\author{
ALPHONSE R. BURDI AND JOHN H. LILLIE \\ Department of Anatomy, The University of Michigan, \\ Ann Arbor, Michigan
}

\begin{abstract}
Human embryos aged six and one-half through 12 weeks were studied to determine the morphological changes in shape of the maxillary dental arch during this early developmental period. Age was determined by crown-rump lengths using the table of Patten ('53).

When compared to a reference catenary curve, the embryonic dental arch exhibited several time-linked and directional changes in shape. First, 6.5 to 8 week embryos characteristically had upper dental arches which were wide and anteroposteriorly flattened and did not conform to the catenary curve. At 7.5 to 9 weeks, the C-shaped dental arch showed more elongation and increasing depth. It was not until weeks 9.5 to 12 that the embryonic dental arch grew enough to conform to the catenary curve.

It is suggested that the catenary curvature of the postnatal upper dental arch can be first recognized as early as 9.5 weeks of development.
\end{abstract}

On the basis of qualitative observations, the general shape of the human postnatal maxillary dental arch has been described as semiellipsoid (Black, 1894), paraboloid (Angle, 1899), U-shaped, rotund, and horseshoe-shaped (Martin, '14; Hrdlicka, '20). Using occlusal contact points as specific landmarks, MacConaill and Scher ('49) quantitatively indicated the curvature of the "common occlusal line" was typically described by a catenary curve. The catenary is a geometric curve produced by a chain of many links suspended by its ends but otherwise allowed to hang freely and has been conveniently used as a reference standard. Scott ('57a) has suggested that both the embryonic dental lamina and later the dental organs of the human deciduous tooth germs were arranged in the form of a catenary curve.

The aims of this study are (1) to determine if the shape of the human prenatal maxillary dental arch is indeed catenary, (2) to describe the temporal sequence in the morphogenesis of catenary arch shape, if it is present, and (3) to correlate arch shape with possible mechanisms in the dynamics of facial growth during early human prenatal development.

\section{MATERIALS AND METHODS}

Fifteen human embryos ranging in age from six and one-half through 12 weeks
(20 through $75 \mathrm{~mm}$ crown-rump length) were studied (table 1). This series represented stages in tooth development from the presence of the dental lamina to the presence of ten maxillary deciduous dental organs.

After fixation in $10 \%$ neutral buffered formalin, each embryo was histologically prepared and frontally sectioned at $10 \mu$. Sections were serially mounted and stained either with a Masson triple-stain or with hematoxylin and eosin. The maxillofacial region of each embryo was then studied by (1) light microscopy to observe developmental tissue changes, (2) wax-plate reconstructions to gain a detailed threedimensional model of the dental arch, and (3) graphic reconstructions for measurements of changing size and shape. Only the latter approach needs further elaboration.

In principle the technique of graphic reconstruction is similar to the traditional wax-plate reconstruction technique. Each serial section was projected and traced at a predetermined magnification. A reference perpendicular was then constructed on each tracing so that the line passed

\footnotetext{
1 This investigation was supported by research grant HD 00178 from the National Institute of Child Health and Human Development, grant 7 from the Horace $H$. Rackham School of Graduate Studies, The University of Michigan, and by a dental student research fellow. ship from the National Institute of Dental Research (USPHS 1 SDI-FR 05321).
} 
TABLE 1

Human embryos used in this study ${ }^{1}$

\begin{tabular}{|c|c|c|c|c|}
\hline No. & $\begin{array}{l}\text { Embryo } \\
\text { number }\end{array}$ & $\begin{array}{c}\text { Crown-rump } \\
\text { length }\end{array}$ & Est. age & Characteristic features of tooth development 2 \\
\hline 1 & EH 600 & $\begin{array}{c}m m \\
20\end{array}$ & $\begin{array}{c}\text { weeks } \\
6.5\end{array}$ & $\begin{array}{l}\text { Dental lamina newly differentiated as a wide and } \\
\text { shallow epithelial thickening near the free } \\
\text { margin of the jaws. }\end{array}$ \\
\hline 2 & EH 231 & 21 & 7.0 & $\begin{array}{l}\text { Dental lamina present with no evidence of dental } \\
\text { organs. }\end{array}$ \\
\hline 3 & EH 880 & 24 & 7.5 & $\begin{array}{l}\text { Dental lamina present with no evidence of dental } \\
\text { organs. }\end{array}$ \\
\hline 4 & EH 739 & 22 & 7.0 & $\begin{array}{l}\text { Budding proliferation of dental lamina at six sites } \\
\text { showing a basal layer of low columnar cells con- } \\
\text { tinuous with basal layer of the oral epithelium, } \\
\text { and a more central mass of larger polyhedral } \\
\text { cells. Sites correspond to central incisors (2), } \\
\text { cuspids (2), and first molars (2). }\end{array}$ \\
\hline 5 & EH 892 & 27 & 8.0 & $\begin{array}{l}\text { Eight dental organs in the early cap stage are } \\
\text { present representing all the primary dentition } \\
\text { except the second molars. Organs show some } \\
\text { invagination facing a condensed zone of mesen- } \\
\text { chyme. }\end{array}$ \\
\hline 6 & EH $15 A$ & 30 & 8.0 & Eight organs present in early to mid-cap stages. \\
\hline 7 & EH 785 & 35 & $\mathbf{8 . 5}$ & Eight organs present in early to mid-cap stages. \\
\hline 8 & EH 678 & 30 & 8.0 & Eight dental organs present in their mid-cap stage. \\
\hline 9 & EH 523 & 36 & 8.5 & Eight dental organs present in their mid-cap stage. \\
\hline 10 & EH 882 & 29 & 8.0 & $\begin{array}{l}\text { Eight dental organs present in their mid to late } \\
\text { cap stage. }\end{array}$ \\
\hline 11 & EH 946 & 34 & 8.5 & $\begin{array}{l}\text { Eight dental organs present in their mid to late } \\
\text { cap stage. }\end{array}$ \\
\hline 12 & EH 479 & 36 & 8.5 & $\begin{array}{l}\text { Eight dental organs present in their mid to late } \\
\text { cap stage. }\end{array}$ \\
\hline 13 & EH 356 & 45 & 9.0 & Eight dental organs present in their late cap stage. \\
\hline 14 & EH 784 & 55 & 10.0 & $\begin{array}{l}\text { Ten dental organs present in their early bell stage } \\
\text { except for the second molars which are in their } \\
\text { early cap stage. }\end{array}$ \\
\hline 15 & EH 628 & 75 & 12.0 & $\begin{array}{l}\text { Full complement }(10) \text { of maxillary deciduous } \\
\text { dental organs present in late cap to early bell } \\
\text { stages; dental lamina shows degeneration be- } \\
\text { tween central incisor organs. }\end{array}$ \\
\hline
\end{tabular}

1 From the Embryological Research Collection, Dept. of Anatomy, The University of Michigan.

2 Generally development of dental organs in the maxillary deciduous arch begins mesially with the incisors and progresses distally to the second molar.

through the middle of the frontally sectioned nasal septum and, whenever present, through epithelial remnants of palatal shelf fusion which were evident as a midline raphe. Using this constructed reference line, distances of dental organs and dental lamina from the midline were measured to the nearest millimeter.
Values for each measurement were then transferred to millimeter-ruled graph paper upon which was arbitrarily placed a line corresponding to the constructed reference perpendicular on the tracing. In addition, space on each graph was allotted to equal the thickness of each projected serial section multiplied by the magnification factor, 
e.g., $10 \mu$ section thickness $\times 100$ times enlargement equals $1,000 \mu$ or $1.0 \mathrm{~mm}$ of space.

Photographs of each complete graphic reconstruction were used to measure proportional changes as well as conformity or non-conformity to the geometric catenary curve. The latter analysis required the design and use of a catenometer which consisted of a standard $200 \mathrm{~mm}$ fine-linked chain suspended at each end from a rigidly mounted metric vernier caliper and allowed to hang freely (fig. 1). The loop of the hanging chain took the form of a catenary curve which was then used as the reference curve of this study. Each photograph was set in a grid coordinate system behind the hanging chain to prevent any parallax. The chain was aligned, by inspection, on each reconstructed arch either to (1) cover the lateral and poste- rior-most portions of the dental lamina of the youngest specimens in which the dental lamina was the predominant structure or (2) to cover the greatest number of dental organs, on center, postero-lateral to the incisal region in older specimens. The character of alignment of each arch to the catenometer was recorded photographically.

Arch form was quantitatively expressed using the formula reported by MacConaill and Scher ('49) in their catenary analyses of the adult dental arch. The radius of curvature $(R)$ of the catenary at its apex was determined by the formula $R=\frac{S^{2}-H^{H}}{2 H}$. The value for $R$ is a quantity which defines any catenary uniquely - just as the radius of a circle defines that circle uniquely. Value $\mathbf{S}$ was equal to one-half the total length of the catenometer chain and $\mathrm{H}$ represented the vertical distance

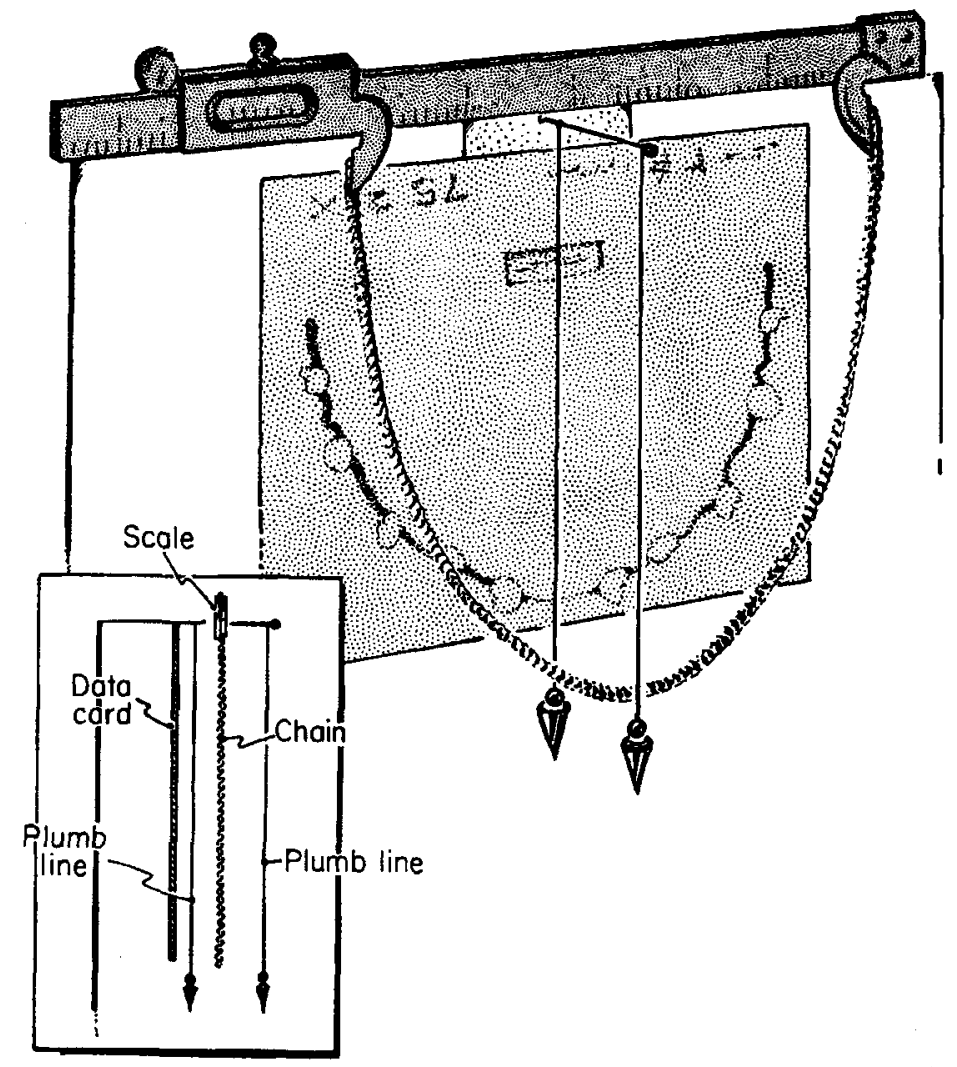

Fig. 1 Catenometer built on vernier caliper shows the reference catenary chain superimposed on a reconstructed dental arch. The inset identifies each part of the catenometer in side view. 
TABLE 2

Catenary numbers expressing changes in shape of maxillary dental arch and palate

\begin{tabular}{|c|c|c|c|c|c|}
\hline No. & $\begin{array}{l}\text { Embryo } \\
\text { number }\end{array}$ & $\begin{array}{c}\text { Crown.rump } \\
\text { length }\end{array}$ & $\mathbf{H}$ & $\mathbf{R}$ & $\begin{array}{c}\text { Catenary } \\
\text { number }\end{array}$ \\
\hline & & $m m$ & $\mathrm{~cm}$ & $\mathrm{~cm}$ & \\
\hline 1 & EH 600 & 20 & 8.46 & 1.68 & 90.10 \\
\hline 2 & EH 231 & 21 & 8.46 & 1.68 & 90.10 \\
\hline$\overline{3}$ & EH 880 & 24 & 8.60 & 1.51 & 81.10 \\
\hline 4 & EH 739 & 22 & 8.42 & 1.73 & 93.00 \\
\hline 5 & EH 892 & 27 & 8.30 & 1.87 & 95.90 \\
\hline 6 & EH 15A & 30 & 8.30 & 1.87 & 95.90 \\
\hline 7 & EH 785 & 35 & 7.80 & 2.51 & 106.00 \\
\hline 8 & EH 678 & 30 & 8.60 & 1.51 & 81.00 \\
\hline 9 & EH 523 & 36 & 8.60 & 1.51 & 81.00 \\
\hline 10 & EH 882 & 29 & 8.95 & 1.11 & 70.50 \\
\hline 11 & EH 946 & 34 & 8.70 & 1.40 & 78.80 \\
\hline 12 & EH 479 & 36 & 8.75 & 1.34 & 76.00 \\
\hline 13 & EH 356 & 45 & 8.70 & 1.40 & 78.80 \\
\hline 14 & EH 784 & 55 & 9.00 & 1.06 & 68.70 \\
\hline 15 & EH 628 & 75 & 8.90 & 1.17 & 75.00 \\
\hline
\end{tabular}

from the curve apex to the horizontal plane formed by the caliper. This vertical line $H$ should divide the chain into two equal halves. The distance between attached arms or ends of the chain, i.e., catenary number, was a convenient expression of arch shape since the catenary number was inversely related to the apical curvature. That is, when the apical curvature is great then the arms of the catenary curve are close together and the catenary number is small.

Changes in shape and proportionality were also expressed as anterior and posterior dental arch indices whenever dental organs were present. The former index was the ratio between the intercuspid width and the sagittal distance from that line to the anterior-most tip of the arch. The latter expressed the ratio between the right and left distal extremities of the arch and the sagittal distance from that line to the line connecting the centers of the two deciduous cuspid dental organs. Unlike the catenary analyses, the values of these indices were based on absolute dimensions at a given magnification.

\section{RESULTS}

The human maxillary deciduous arch and palate underwent several changes in shape relative to its conformity or nonconformity to the reference catenary curve. As shown in table 2 , there was a decrease in the radius of arch curvature (R) and a decrease in catenary number as the crown-rump length of the embryo increased. As a corollary to these changes, the depth of the total maxillary arch (value $\mathbf{H}$ ) increased progressively. Figure 2 demonstrates these changing relationships between the reconstructed arches and the superimposed catenary chain. In the developmental span from $20-75 \mathrm{~mm}$ CRL (6.5-12 weeks), the maxillary dental arch had an early period of non-conformity followed by a late period of conformity to the catenary curve. An intermediate period also was observed.

During the sixth and one-half through eighth weeks of development (20-30 mm CRL), the maxillary deciduous arch of each embryo was flattened anteroposteriorly with a marked non-conformity between the shape of the catenary chain and the incisal portion of the arch. Embryos in the intermediate phase (7.5-9 weeks, 30-36 mm CRL) had arches with lesser radii of curvature which, consequently, appeared more elongate. In these intermediate phase arches the discrepancy between arch form and the catenary chain was reduced from that of the earlier phase of non-conformity. The final group of embryos (9.5-12 weeks, 45-75 mm CRL) had maxillary deciduous arches which were in relatively complete conformity with the superimposed catenary chain, i.e., the phase of conformity. It should be noted that the transition between phases was gradual.

Results from the catenary analyses were supported by length-width ratios developed for the anterior and posterior arch regions. 

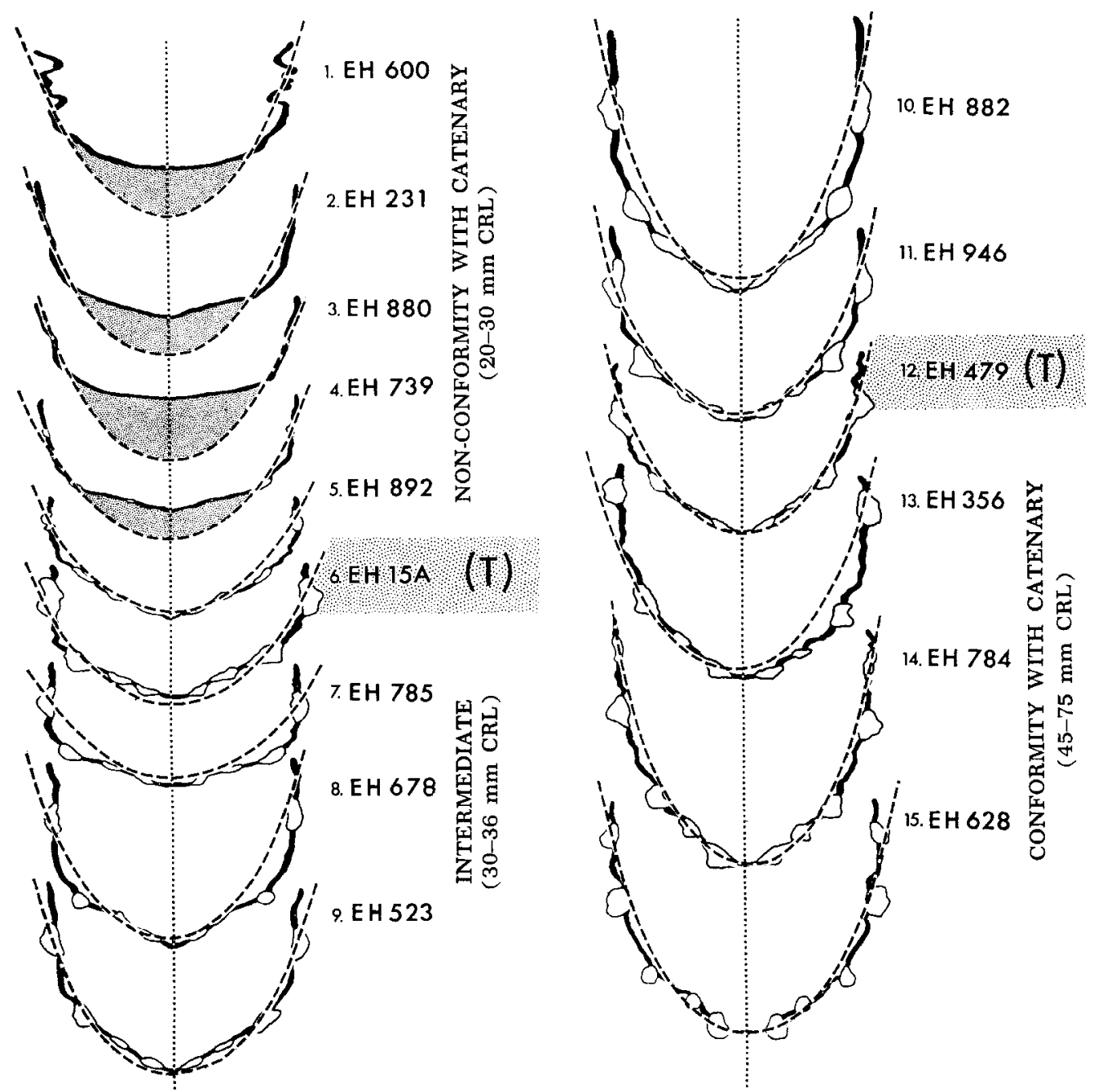

Fig. 2 The three developmental phases in the formation of the catenary dental arch curvature during the embryonic period. Each arch is shown with the superimposed catenary chain. Note that embryos EH 15A and EH 479 (shaded labels) have transition type arches.

When the distance between right and left cuspid dental organs, i.e., intercuspid line, was related to the depth of the arch anterior to it, it was observed that the length of the anterior arch showed an increase which was in contrast to a general relative decrease in intercuspid width (table 3 ). Posterior arch ratios between posterior arch width and depth similarly showed a progressive increase with increasing crownrump length (table 4 ). Composite length measurements for posterior and anterior arch regions characteristically increased with crown-rump length. Conversely, the series of anterior and posterior arch widths decreased relatively as the crown-rump lengths of the population increased from 22-75 mm CRL.

\section{DISCUSSION}

The deciduous dental arch of the upper jaw exhibits several changes in shape during human embryonic development. In this study, changes in dental arch shape are both time-linked and directional. During the sixth and one-half through eighth 
TABLE 3

Anterior arch index

\begin{tabular}{|c|c|c|c|c|c|c|}
\hline No. & $\begin{array}{l}\text { Embryo } \\
\text { number }\end{array}$ & $\begin{array}{c}\text { Crown-rump } \\
\text { length }\end{array}$ & $\underset{(\times) \text { (normal) }}{\text { Magnification }}$ & $\begin{array}{l}\text { Anterior } \\
\text { arch } \\
\text { length }\end{array}$ & $\begin{array}{c}\text { Intercuspid } \\
\text { width }\end{array}$ & Index \\
\hline & & $m m$ & & $m m$ & $m m$ & $\%$ \\
\hline $1^{1}$ & EH 600 & 20 & $\times 75$ & - & - & - \\
\hline $2^{1}$ & EH 231 & 21 & $\times 75$ & - & - & - \\
\hline $3^{1}$ & EH 880 & 24 & $\times 75$ & - & - & - \\
\hline 4 & EH 739 & 22 & $\times 75$ & 20 & 142 & $14.1^{2}$ \\
\hline 5 & EH 892 & 27 & $\times 75$ & 33 & 140 & $23.6=$ \\
\hline 6 & EH 15A & 30 & $\times 50$ & 20 & 91 & 21.9 \\
\hline 7 & EH 785 & 35 & $\times 50$ & 20 & 120 & 16.7 \\
\hline 8 & EH 678 & 30 & $\times 50$ & 27 & 100 & 27.0 \\
\hline 9 & EH 523 & 36 & $\times 50$ & 27 & 90 & 30.0 \\
\hline 10 & $\mathrm{EH} \mathbf{8 8 2}$ & 29 & $\times 50$ & 39 & 90 & 43.3 \\
\hline 11 & EH 946 & 34 & $\times 50$ & 37 & 114 & 32.4 \\
\hline 12 & EH 479 & 36 & $\times 50$ & 37 & 116 & 31.9 \\
\hline 13 & EH 356 & 45 & $\times 50$ & 39 & 108 & 36.1 \\
\hline 14 & E.H 784 & 55 & $\times 50$ & 42 & 116 & 36.2 \\
\hline 15 & $\mathrm{EH} 628$ & 75 & $\times 25$ & 33 & 120 & 27.5 \\
\hline
\end{tabular}

1 Cuspid dental organs were not present; therefore, indices could not be developed.

2 Index value corrected to $\times 50$.

TABLE 4

Posterior arch index

\begin{tabular}{|c|c|c|c|c|c|c|}
\hline No. & $\begin{array}{l}\text { Embryo } \\
\text { number }\end{array}$ & $\begin{array}{c}\text { Crown-rump } \\
\text { length }\end{array}$ & $\begin{array}{l}\text { Magnification } \\
(x) \text { (normal) }\end{array}$ & $\begin{array}{c}\text { Posterior } \\
\text { arch } \\
\text { length }\end{array}$ & $\begin{array}{c}\text { Posterior } \\
\text { arch } \\
\text { width }\end{array}$ & Index \\
\hline & & $m m$ & & $m m$ & $m m$ & $\%$ \\
\hline 11 & EH 600 & 20 & $\times 75$ & - & - & - \\
\hline $2^{1}$ & EH 231 & 21 & $\times 75$ & - & - & - \\
\hline $3^{1}$ & EH 880 & 24 & $\times 75$ & - & - & - \\
\hline 4 & EH 739 & 22 & $\begin{array}{r}75 \\
\times 7\end{array}$ & 67 & 193 & $34.7^{2}$ \\
\hline 5 & EH 892 & 27 & $\times 75$ & 61 & 192 & $31.6^{2}$ \\
\hline 6 & EH 15A & 30 & $\times 50$ & 44 & 126 & 34.9 \\
\hline 7 & EH 785 & 35 & $\times 50$ & 54 & 145 & 37.2 \\
\hline 8 & EH 678 & 30 & $\times 50$ & 74 & 134 & 55.2 \\
\hline 9 & EH 523 & 36 & $\times 50$ & 65 & 130 & 50.0 \\
\hline 10 & EH 882 & 29 & $\times 50$ & 79 & 110 & 71.8 \\
\hline 11 & EH 946 & 34 & $\times 50$ & 85 & 155 & 54.8 \\
\hline 12 & ЕH 479 & 36 & $\times 50$ & 83 & 170 & 48.8 \\
\hline 13 & EH 356 & 45 & $\times 50$ & 76 & 134 & 56.7 \\
\hline 14 & EH 784 & 55 & $\times 50$ & 118 & 170 & 69.4 \\
\hline 15 & EH 628 & 75 & $\times 25$ & 113 & 160 & $70.6^{2}$ \\
\hline
\end{tabular}

1 Cuspid dental organs were not present; therefore, indices could not be developed.

2 Index value corrected to $\times 50$.

weeks in utero, the dental lamina appears as an epithelial thickening from the lining of the oral cavity. With continued growth, the dental lamina invades the maxillary mesoderm to run arch-like along the free margin of the upper jaw. The arch of the dental lamina is characteristically wide and anteroposteriorly flattened. Later with the appearance of dental organs in their late cap stage of development ( 7.5 to 9 weeks, $30-36 \mathrm{~mm} \mathrm{CRL),} \mathrm{the} \mathrm{C-shaped}$ dental arch shows some elongation and increased depth. Yet, at this time there is still a lack of conformity to the reference catenary curve. With further growth and epithelial proliferation of the dental organs, the dental arch of older embryos (9.5 to 12 weeks, $45-75 \mathrm{~mm}$ CRL) conforms completely with the reference catenary curve.

It may be significant to relate these changes in the embryonic dental arch with the report by MacConaill and Scher ('49) who stated that the catenary was the curvature which best fit the postnatal dental arch. On the question of when in human 
development the catenary dental arch first develops, Scott ('57a) inferred that the postnatal catenary curvature could be traced back into the early embryonic period when the dental lamina first develops. Lacking direct observations of the dental arch itself, this inference was made on the basis that the embryonic skeleton, i.e., the nasal capsule, of the upper face had a catenary form at its base and that the dental lamina arching around the periphery of the capsule would likewise conform to a catenary curve. The findings of the present study serve to refine, if not correct, Scott's stimulating inference.

Since the dental arch extends around the periphery of the developing palatal region, this close spatial relationship suggests that the dental lamina and its daughter dental organs can be used as a convenient anatomical boundary for the palate. Recent experimental studies (Jacobs, '64a, '64b), based specifically on dissecting palates from embryos, reported the quantitative differences in palatal weights and in concentrations of palatal sulfated-mucopolysaccharides between normal and cleft palate embryos. Yet, the palates were dissected out without defining any clear cut peripheral palatal boundary, i.e., dental arch.

This close anatomical relationship and similarity between dental arch and palate is further emphasized by Freiband's ('37) classic anthropometric study of palatal shape in 102 human fetuses. Although palatal shapes were not related to any reference curve as the catenary of the present study, Freiband did observe that the most characteristic feature of palatal growth during fetal development was a preponderance of elongate or dolichouranic palates. Comparison of his figures with the present findings of the dental arch showed that both conform to a catenary curve.

Having set forth the sequence of morphological patterns during the development of the catenary shaped dental arch in human embryogenesis, we next turn our attention to the interesting question of the possible growth mechanisms related to the early changes in arch form. Change in shape of the embryonic dental arch is not a haphazard affair but appears to be a carefully coordinated pattern of dimen- sional as well as directional growth of all the tissues which surround the dental arch. Thus, this would involve the developing soft tissue matrix of the head, the cartilaginous nasal capsule, and then the bony craniofacial skeleton.

Prior to the development of either a cartilaginous or bony facial skeleton, the size and form of the relatively flattened embryonic face is dependent upon the accelerating and decelerating growth of the mesenchymal masses underlying each of the facial primordia (Patten, '61). Normally with the fusion of the several originally separate facial primordia, the face appears to grow as a soft tissue unit, or en masse, with recognizable differential growth rates in more localized regions. This unit type of growth continues even as the cartilaginous nasal capsule develops within and supports the soft tissue matrix of the head. In addition to the supportive role, the relatively rapid growth of the cartilaginous skeleton has also been assigned a primary effector role in the forward growth of the embryonic craniofacial reregion in normal (Scott, '53, '57b, '59) and abnormal (Avery, '62) development. Since the cartilage of the nasal capsule is the predominant tissue in the area at the time when the dental arch elongates to conform to the catenary, it appears that chondral growth is specifically responsible for arch elongation. The subsequent appearance of ossification centers surrounding the nasal capsule is interesting in that arch elongation is temporally correlated with the first appearance of ossification centers for the premaxillary and maxillary bones in the cuspid region of the dental arch. These ossification centers have no typical sutures joining them at this stage of development. This would suggest that the sutural theory of facial growth (Weinmann and Sicher, '55) is an unlikely mechanism at this stage of development. The consolidation of the bony premaxillary and maxillary centers soon after their appearance in the eighth week (Woo, '49; Kraus, '60; Kraus and Decker, '60) does suggest, however, that as the soft tissue matrix of the face grows and migrates as a unit under the influence of the nasal capsule so does the consolidated premaxillary-maxillary complex. 
Once the consolidation of the premaxillary and maxillary ossification centers occurs, it appears that the newly formed catenary dental arch begins a period of shape stability which, as previously indicated, continues into postnatal life.

The relationship between arch shape, arch stability and consolidation of premaxillary and maxillary facial segments has further significance. In sheep, dog, and pig, there is normally no early bony fusion at the premaxillary-maxillary suture which is said to account for their elongated and narrow dental arches as well as the pronounced diastema between cuspid and incisor teeth. The significance of nonconsolidation is further shown in unoperated cases of bilateral cleft lip and palate in children (Glass, '56; Stark, '61). In these instances, there is neither a soft tissue nor bony bridge between the premaxillary and maxillary facial segments. Characteristically related to this abnormal gap, spatially comparable to the diastema, is an elongated dental arch that is clearly noncatenary. Once surgically corrected, the dental arch does regain some conformance to a typical catenary curvature.

\section{LITERATURE CITED}

Angle, E. H. 1899 Classification of malocclusion. Dent. Cosmos, 41: 248-264.

Avery, J. K. 1962 The nasal capsule in cleft palate. Anat. Anz., 109: 722-726.

Black, G. V. 1894 Descriptive Anatomy of the Human Teeth. Wilmington Dental Mfg. Co., Phila., pp. 135-148.

Freiband, B. 1937 Growth of the palate in the human fetus. J. Dent. Res., 16: 103-122.

Glass, D. F. 1956 Maxillary growth and its application to the unoperated cleft of lip and palate. Europ. Orthod. Soc., 32nd Congress, pp. 249-257.
Hrdlicka, A. 1920 Practical Anthropometry. Wistar Institute of Anatomy and Biology, Phila., Chap. III, pp. 123-181.

Jacobs, R. M. 1964a S35-liquid-scintillation $^{35}$ count analysis of morphogenesis and teratogenesis of the palate in mouse embryos. Anat. Rec., 150: 271-277.

1964b Preliminary survey of the effects of cortisone upon palate formation, litter size, and fetal weight in CD-1 strain of mice. J. Dent. Res., 43: 715.

Kraus, B. S. 1960 Prenatal growth and morphology of the human bony palate. J. Dent. Res., 39: 1177-1199.

Kraus, B. S., and J. D. Decker 1960 The prenatal inter-relations of the maxilla and premaxilla in the facial development of man. Acta Anat., 40: 278-294.

MacConaill, M. A., and E. A. Scher 1949 Ideal form of the human dental arcade with some prosthetic application. Dent. Record, 69: 285302.

Martin, R. 1914 Lehrbuch der Anthropologie. G. Fischer, Jena, Chap. III, pp. 886-890.

Patten, B. M. 1953 Human Embryology. McGraw-Hill Book Co., Inc., New York, Chap. VII, pp. 181-198.

1961 Congenital Anomalies of the Face and Associated Structures. Ed. by S. Pruzansky. Charles C Thomas Co., Springfield, Chap. I, pp. $11-45$.

Scott, J. H. 1953 The cartilage of the nasal septum. Brit. Dent. J., 95: 37-43.

1957a The shape of the dental arches. J. Dent. Res., 36: 996-1003.

1957b The determination of palate form. Dent. Pract., 7: 344-345.

1959 The growth of the nasal cavities. Acta Oto-Laryng., 50: 215-224.

Stark, R. B. 1961 Congenital Anomalies of the Face and Associated Structures. Ed. by $S$. Pruzansky, Charles C Thomas Co., Springfield, Chap. IV, pp. 66-84.

Weinmann, J. P., and H. Sicher 1955 Bone and Bones - Fundamentals of Bone Biology. C. V. Mosby Co., St. Louis, Chap. II, pp. 47-138.

Woo, J. K. 1949 Ossification and growth of the human maxilla premaxilla and palate bone. Anat. Rec., 105: 737-762. 